\title{
The effects of methylphenidate and d-amphetamine related to route of administration
}

\author{
E. S. SMITH and W. ISAAC \\ University of Georgia, Athens, Georgia 30602
}

The effects of methylphenidate hydrochloride and d-amphetamine sulfate were compared when given orally and by intraperitoneal injection to rats. Both drugs increased the level of locomotor activity when given by injection. Oral administration of d-amphetamine produced a lesser effect, but methylphenidate was ineffective when given by this route.

Ritalin, or methylphenidate hydrochloride (MP), and Dexedrine, or dextroamphetamine sulfate (DA), have been commonly used in the treatment of hyperactive children (Fischer \& Wilson, 197.1; Werry \& Sprague, 1970). MP has been the preferred drug, with DA the second choice, from a number of drugs, including stimulants, anticonvulsants, and antipsychotic drugs (Millichap, 1968). While administrations of both MP and DA increase activity in the rat (Kallman \& Isaac, 1975), it has been observed that DA serves to reduce activity in the squirrel monkey (Isaac \& Troelstrup, 1969). MP has been distinguished by its lack of effect upon a variety of behaviors of the squirrel monkey (Delay, Steiner, \& Isaac, 1979; Goethe \& Isaac, 1977), including locomotor activity (Isaac \& Kallman, 1979).

In addition to the obvious difficulties inherent in any interspecies comparison, interpretation of the observed differences obtained with MP in rats and monkeys is made more difficult by the different routes of administration that have been employed with the two groups of subjects. To reduce trauma associated with drug administration, we have used an oral route when drugging monkeys, whereas more convenient intraperitoneal injections are commonly used to administer the drug to rats.

In an attempt to understand the inconsistent results obtained with the two drugs in rats and squirrel monkeys, the present study was designed to compare the efficacy of the two drugs in altering locomotor activity when given by both the oral and intraperitoneal routes of administration to the rat.

This research was supported by Research Grant MH 25164 from the National Institute of Mental Health. Methylphenidate hydrochloride was generously provided by Ciba-Giegy Corporation, and d-amphetamine sulfate was generously provided by Smith, Kline, and French Laboratories. Reprint requests should be sent to Walter Isaac, Department of Psychology, University of Georgia, Athens, Georgia 30602.

\section{METHOD}

\section{Subjects}

The subjects, 24 male albino rats (SAF/SDD) were 28 days of age at the beginning of the study. The animals were allowed to adapt to the laboratory conditions for 1 week before the study began. A 12:12 light-dark schedule was maintained in the colony room. A 23.5-h water-deprivation schedule was maintained, with food available in the home cages at all times.

\section{Apparatus}

Activity measures were taken in a sound-treated room containing 12 cubicles, each of which was also constructed to reduce both transmitted and reflected sound. Within each cubicle, a subject was housed in a plastic mouse-breeding cage $(45 \mathrm{~cm}$ long, $24 \mathrm{~cm}$ wide, $15 \mathrm{~cm}$ high). An infrared light beam bisected the length of the cage and fell on an infrared-sensitive phototransistor. Beam breakings produced by movements of the rats were recorded by solid state counters in another room. Cumulative counts were entered into each counter's memory bank every $10 \mathrm{~min}$. Each cubicle was illuminated by a 20 -W Kenrad fluorescent light, producing $2,000 \mathrm{~lx} \pm 50 \mathrm{lux}$ at the floor of each cage.

\section{Procedure}

In a preliminary study, it was found that the major drug effects were seen during the 1 st hour of activity measurement, and a 2nd hour of data gathering added no further information. It was also observed that the greatest drug effects were obtained in the light, and the effects seen in the dark were minimal. Further, it was determined that there were no unusual immediate effects of the drugs that might be overlooked during the short time required to drug the group of animals.

In the present study, each experimental session lasted $70 \mathrm{~min}$, with the first 10 min serving as an adaptation period. The following hour was divided into six intervals of 10 min each, with separate scores obtained for each interval. All activity measures were obtained between 2:00 p.m. and 6:00 p.m.

One half of the subjects were administered DA, and one half were administered MP. One half of the subjects under each drug condition were administered drugs by intraperitoneal injections, and the other half were administered drugs orally in sugar water. Those animals receiving oral administration of the drugs were administered placebo injections of sterile water each day, and those receiving their drugs by intraperitoneal injections were given undrugged sugar water each day.

In the oral administration of the drugs and placebo, the solution was presented in watch glasses $50 \mathrm{~mm}$ in diameter, mounted in 
square wooden blocks with sides of $63.5 \mathrm{~mm}$ that were $12.5 \mathrm{~mm}$ thick. Plexiglas covers with a central opening $38.5 \mathrm{~mm}$ in diameter were centered over the watch glasses to allow ready access to the fluid but to reduce spillage. Drug solutions were prepared for injections so that constant-volume injections $(1 \mathrm{ml} / \mathrm{kg})$ were possible. All subjects were given access to untreated water for 5 min immediately following drug administration to facilitate the absorption of the oral dose and to reduce the effects of the water deprivation.

Drug dosages were based on body weight and were administered within $20 \mathrm{~min}$ before the collection of data began. The doses of MP used were placebo, $3.2 \mathrm{mg} / \mathrm{kg}$, and $6.4 \mathrm{mg} / \mathrm{kg}$; the doses of DA used were placebo, $.8 \mathrm{mg} / \mathrm{kg}$, and $1.6 \mathrm{mg} / \mathrm{kg}$. Each subject received a single dose of its drug each day, with the order of drug dosage in each replication determined by a Latin square design. A total of seven replications were run, with each replication requiring 3 days. During the first four replications, the subjects were adapted to the handling and drugging procedures, the testing situation, and any altered physiological conditions that might be produced by the drugs. Only the data from the last three replications were included in the analysis of the results.

\section{RESULTS}

As recommended by Edwards (1972) for frequency data, a $\sqrt{\mathrm{X}+1}$ transformation was performed on the frequencies of beam breakings before the data were analyzed. A separate analysis of variance was used to evaluate the data obtained under the two drugs. Appropriate error terms were used to evaluate the effects of independent and related measures, using a pooled error term in the latter case (Edwards, 1972).

As may be seen in Figure 1, increasing levels of DA produced an increase in locomotor activity $[F(2,170)=$ $278.08, \mathrm{p}<.01$ ], although the route of administration altered the magnitude of the drug's effect $[F(1,10)=7.23, p<.05]$. The differing effectiveness of the drug administered by the two routes produced a significant interaction between doses and routes of administration $[F(2,170)=39.75, p<.01]$. Intraperitoneal injection produced a more immediate drug effect that declined more rapidly than when the drug was administered orally, yielding a significant interaction between intervals and route of administration $[\mathrm{F}(5,170)=2.81, \mathrm{p}<.05]$.

A more complex picture is presented by the analysis of the effects of MP upon locomotor activity (Figure 2). Increasing levels of MP produced an increase in locomotor activity $[\mathrm{F}(2,170)=71.79, \mathrm{p}<.01]$, and again, the route of administration produced a differential effect $[F(1,10)=9.27, p<.05]$. The effect of the drug over the test session was not constant, resulting in a significant difference over the intervals $[F(5,170)=$ $10.28, \mathrm{p}<.01$ ]. Since oral administration of the drug produced no measurable effects upon locomotor activity, whereas administration by intraperitoneal injection produced stimulant effects similar to those of DA, all interactions including the route of administration as one of the terms were significant. The dose effect was not independent of the route of administra-

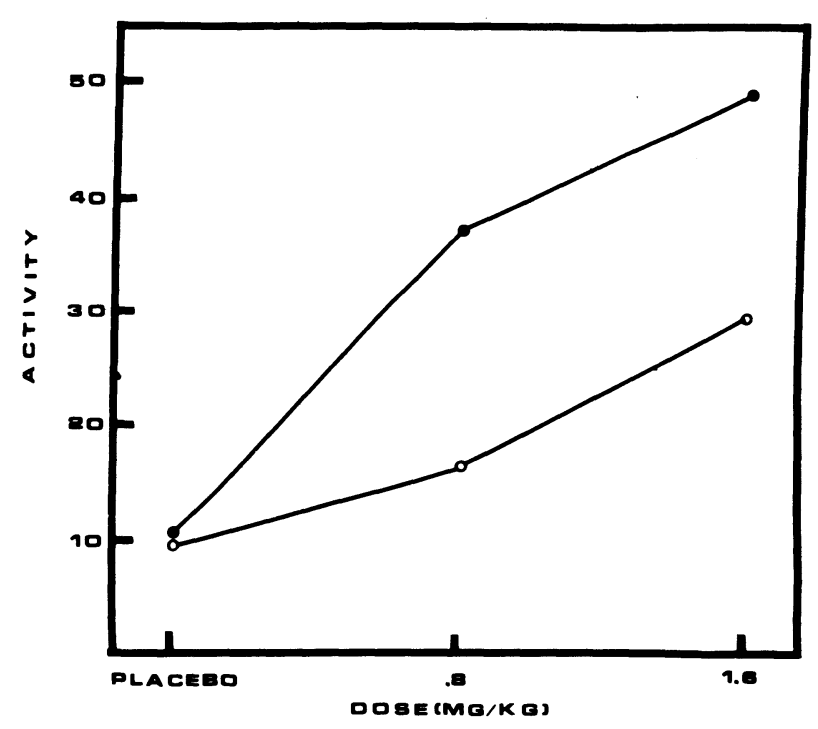

Figure 1. Effects of d-amphetamine sulfate upon mean daily transformed activity scores.

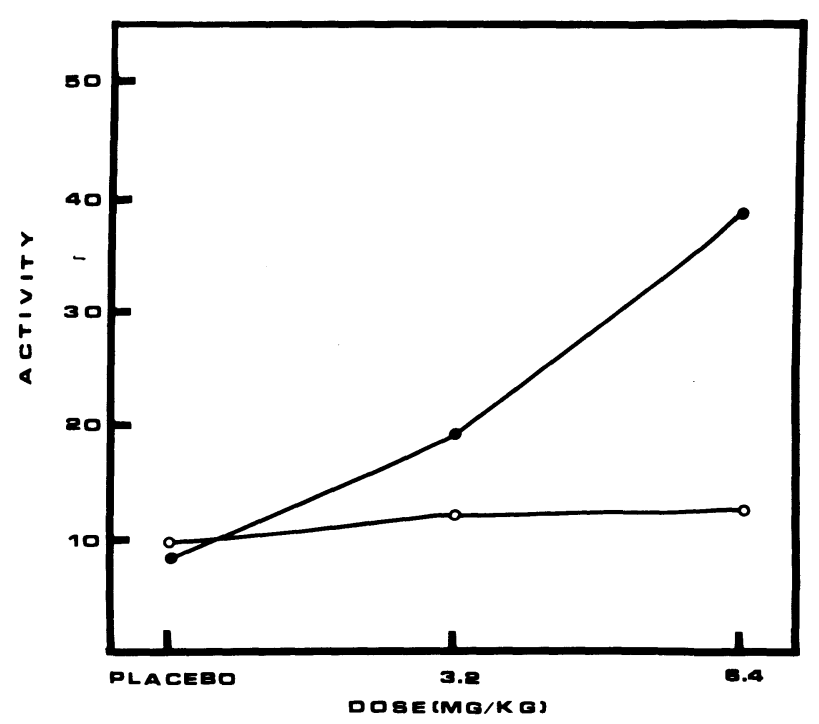

Figure 2. Effects of methylphenidate hydrochloride upon mean daily transformed activity scores.

tion $[\mathrm{F}(2,10)=53.80, \mathrm{p}<.01]$, nor was the intervals effect $[F(5,170)=24.90, p<.01]$. The higher order interaction including the dose effect, intervals, and route was significant as well $[\mathrm{F}(10,170)=6.94, \mathrm{p}<.01]$.

\section{DISCUSSION}

The results of the present study are consistent with earlier findings that intraperitoneal injections of both DA and MP produce an increase in the activity of the rat (Kallman \& Isaac, 1975). The somewhat lesser effect of DA when administered orally is also similar to the effect observed by others (Zieve, 1937). The lack of an effect of MP when administered orally has been previously demonstrated in the squirrel monkey (Delay et al., 1979; Goethe \& Isaac, 1977; Isaac \& Kallman, 1979). The latter observation, however, is at variance with reports of the 
efficacy of MP when administered orally to children in much smaller doses.

A possible explanation for the absence of an effect of orally administered MP may be found in the data reported by Faraj, Israili, Perel, Jenkins, Holtzman, Cucinell, and Dayton (1974). They observed that plasma levels of the drug fell rapidly following intravenous injection but metabolite levels continued to rise for nearly $2 \mathrm{~h}$. They also found that these metabolites were less effective than the parent drug in altering the activity levels of their subjects. It would therefore seem likely that the minimal effect of orally administered MP could be due to a slow absorption of the drug when administered orally combined with a rapid metabolism of the drug, resulting in minimal effects being seen in the behavior of the rat. Plasma levels of DA, on the other hand, have been found to decline slowly after intravenous injection (Axelrod, 1954), as reflected by the behavioral results that were obtained in the present study.

\section{REFERENCES}

Axelrod, J. Studies on sympathomimetic amines. II. The biotransformation and physiological disposition of d-amphetamine, d-p-hydroxyamphetamine and d-methamphetamine. Journal of Pharmacology and Experimental Therapeutics, 1954, 110, 315326.

Delay, E. R., Steiner, N. O., \& IsaAc, W. Effects of damphetamine and methylphenidate upon auditory threshold in the squirrel monkey. Pharmacology, Biochemistry and Behavior, 1979, 10, 861-864.

EDWARDS, A. L. Experimental design in psychological research. New York: Holt, Rinehart, \& Winston, 1972.
Faraj, B. A., Israili, Z. H., Perel, J. M., Jenkins, M. L., Holtzman, S. G., Cucinell, S. A., \& Dayton, P. G. Metabolism of methylphenidate $-{ }^{14} \mathrm{C}$ in man and animals. Journal of Pharmacology and Experimental Therapeutics, 1974, 191, 535-547.

Fischer, K. C., \& Wilson, W. P. Methylphenidate and the hyperkinetic child. Diseases of the Nervous System, 1971, 32, 695-698.

Goethe, K. E., \& Isaac, W. Effects of amphetamine and methylphenidate on fixed-interval responding in the squirrel monkey. Pharmacology, Biochemistry and Behavior, 1977, 7, 78-82.

IsaAc, W., \& Kallman, M. D. Locomotor effects of damphetamine and methylphenidate in young squirrel monkeys. Bulletin of the Psychonomic Society, 1979, 14, 315-317.

IsaAc, W., \& Troelstrup, R. Opposite effects of illumination and d-amphetamine upon activity in the squirrel monkey (Saimiri) and owl monkey (Aotes). Psychopharmacologia (Berlin), 1969, 15, 260-264.

Kallman, W. M., \& Isaac, W. The effects of age and illumination on the dose response curves for three stimulants. Psychopharmacologia (Berlin), 1975, 40, 313-318.

Millichap, J. Drugs in management of hyperkinetic and perceptually handicapped children. Journal of the American Medical Association, 1968, 206, 1527-1530.

Werry, J., \& Sprague, R. Hyperactivity. In C. Costello (Ed.), Symptoms of psychopathology. New York: Wiley, 1970.

ZiEve, L. Effect of benzedrine on activity. Psychological Record, 1937, 1, 393-396.

(Received for publication August 17, 1980.) 